\title{
1. Shit happens, but you have a job to do!
}

\section{Keith Townsend and Mark N.K. Saunders}

The Horse and Groom is a friendly Cotswolds country pub that has consistently won UK 'best public house' awards since $2009 .{ }^{1}$ The quality of this Bourton-on-the-Hill pub is hence a perfect starting point for this unusual research offering. We sat in this country pub after a day of working through a significant and important revision of a research methods article. As we enjoyed a pint of beer, an award-winning dinner and exceptional service, we discussed the differences between textbook research methods and the realities that all of us in the field face on a day-to-day basis. Previously, we had both embarked on publications that drew on the realities (see for example, Townsend and Burgess 2009; and Saunders and Lewis 1997), but felt that there was scope for something new. Something that was both practical but based in experiences.

As a fellow researcher we are sure you can appreciate the excitement that grew throughout the course of the evening as we discussed the possibilities that would become this edition. 'There's so much that goes unwritten', we would lament; 'we're doing our students a disservice by not telling them', we would declare. 'So let's do something', we agreed. It was then that we embarked upon a journey that started the same way that many top research publications start ... on the back of beer mats (see Figure 1.1).

As you can see from the photograph, our plan was literally written on the back of what Mark (being British) calls 'beer mats' and Keith (being Australian) 'beer coasters', with the key final stage 'Talk to Fran tomorrow' as one of us had a meeting the next day with Francine O'Sullivan, our commissioning editor at Edward Elgar Publishing.

One might be forgiven for thinking pubs, beer mats (or coasters!), chats with publishers - doesn't sound all that 'scientific' or high-brow. Perhaps not, but it does reflect the broad experience of reality while not paying enough attention to the many hours of subsequent planning, discussions, reviewing and commenting on drafts that we were about to face.

The chapters in this book are written with a starting point of realising that research projects do not always go smoothly. In fact, we would argue 


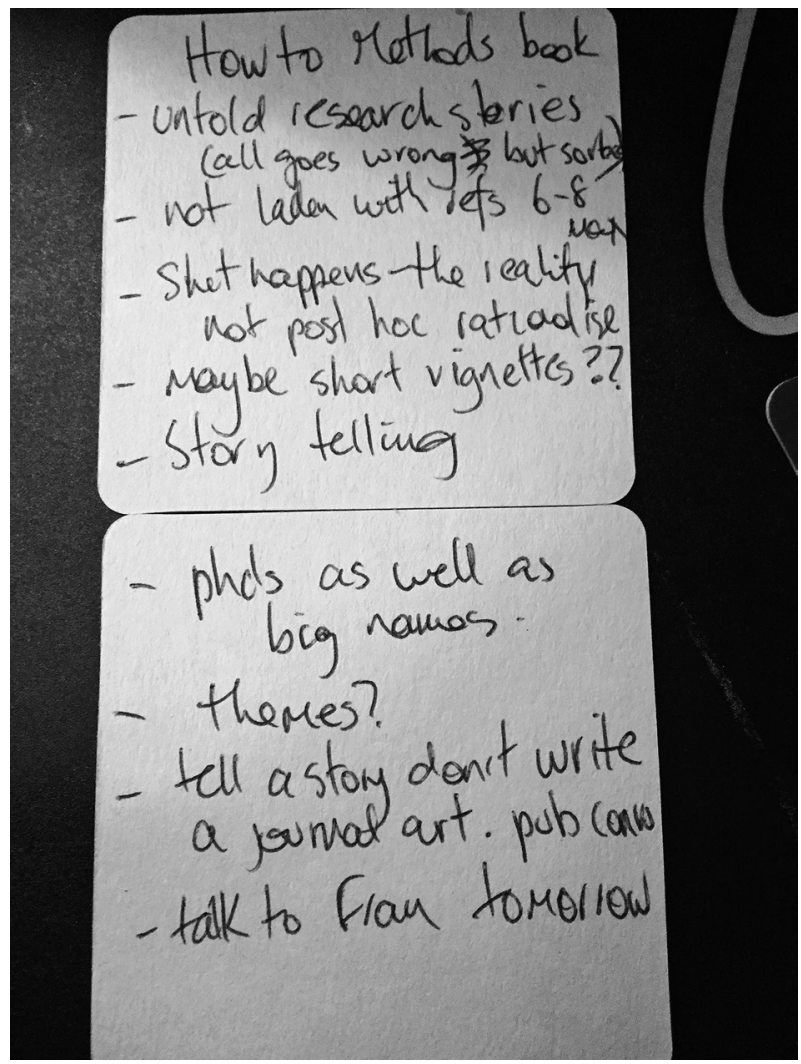

Figure 1.1 Horse and Groom research proposal

that they rarely go smoothly. But we are employed to perform research from conceptualisation of worthwhile projects to the completion of these projects including dissemination to a range of different audiences.

We are not suggesting that 'doing research' is particularly difficult, nor are we suggesting that it is easy - it just is what it is. And we as researchers must find ways to jump through a myriad of invisible hoops and over a plethora of hurdles of unknown heights. So planning is important and the knowledge and understandings we can glean from textbooks and journal articles on research methods are an important part of that planning. But, and this is an important 'but': these textbooks and journal articles rarely are of help regarding what do you do when your research project goes off track, usually offering only sanitised accounts. This book we hope will address this important, and usually hidden, aspect of research. 
Our contributors have provided their own inside accounts in the form of 19 chapters and 14 vignettes offering revealing insights and highlighting their own lessons. We believe these will give hope to the early career researcher, the $\mathrm{PhD}$ or Masters student, and at the same time provide the 'old timers' such as ourselves with some reinvigoration.

Contributors were given strict instructions. This is not to be a theory driven, literature soaked piece of work. Much like the book's inception, we would tell the authors to imagine you were at a pub or a coffee shop and relaying a story to a friend. Keep it informal, keep it light, but tell it as it actually was and have some lessons for the reader to take away.

We have divided the book into four sections. Maintaining the informal theme, the sections are 'Getting started', 'Getting data', 'Getting it together', and 'Getting finished'. Within each section we have chapters followed by short vignettes, all of which tell tales of researchers facing realworld problems or not quite getting things right in the first instance.

In the first section, 'Getting started', we draw on expert experiences in the 'not-so-straightforward' manner in which research projects develop and progress. Bill Lee leads the book with his chapter (2) 'Developing research ideas' and recounts an experience with research on flexible manufacturing systems where the expectations that were drawn from the literature and theory were not aligned with what he was finding empirically. The research project obviously became much more difficult, but indeed, much more interesting! So what does this say about literature reviews? Céline Rojon gives some insights in Chapter 3. There are many 'types' of literature reviews, and her chapter, whilst focusing on the use of systematic literature reviews, also offers insights into traditional narrative reviews, providing some important insights to keep the researcher on track.

The next two chapters in this section focus on the interactions between PhD supervisors and students. In Chapter 4 Jillian Cavanagh, Hannah Meacham and Timothy Bartram explore a number of important themes where all parties within a PhD team must be working together to ensure the success of the research project and in particular successful completion. As part of this they reflect on a few different matters, for example: the differences between the literature review and a theoretical framework; academic writing styles; and key challenges in different supervision styles. Polly Black then, in Chapter 5, outlines a supervision saga that happens all too often: when a supervisor and student are forced to go separate ways, but the $\mathrm{PhD}$ and research project must go on and a new supervisor found! New supervisors, indecision, uncertainty, and a completely different approach to feedback . . . all at a time when the PhD student is at their most vulnerable.

We round out the first section of the book with two vignettes. The first of these (vignette 6) is from Hugh Bainbridge, explaining why a researcher 
with career development in mind needs to differentiate between 'reply' and 'reply all' in an email [editor's note: Keith feels Hugh's pain here having engaged in a similar faux pas]. Our final vignette (7) in this 'getting started' section comes from Deisi Yunga who explores a number of issues in coming up with a research question, including the importance of communication and evaluating rather than acting immediately on every piece of advice.

Once a research project moves from the 'getting started' phase, 'getting data' is often the next hurdle where researchers and research projects can come unstuck. Neve Isaeva opens this section with Chapter 8 , titled 'Finding epistemology', offering what she refers to as a journey of selfdiscovery 'from clueless despair to confident revelation'. Ideally, researchers should have some sense of their epistemology prior to collecting data because this drives many of the decisions around the data that will be collected. However, as Neve illustrates through her story, an epistemological position is something that emerges over time and may not fit neatly into the typologies offered by textbooks.

In Chapter 9 Mark Saunders and David Gray provide us with the first of four chapters focusing on the realities of data collection. Theirs is a panicked description of an online data collection process that began to spiral into desperate territory as questionnaires were not returned and email requests to respondents did not meet the intended people. Not only were their numbers not flowing back in, but the legal threats were arriving! However, as you will read, their research was eventually completed successfully, and lessons were learned. Next, in Chapter 10, Heather Short offers insights about undertaking interviews and, reflecting on her experiences, asks why research participants may be less than truthful. Heather questions whether she was either willing or able to hear the truth and, quoting George Bernard Shaw, asks whether she and her research participants were 'separated by a common language'?

Sharyn Rundle-Thiele, Julia Carins and Christiane Stock's chapter offers insights from a project where data were to be collected using observation. Theirs was an interesting research agenda, looking at the eating and alcohol consumption habits of people within and outside the workplace. What could possibly go wrong? Read Chapter 11 and you'll discover a few things as well as real insights regarding the need to be flexible and roll with the punches! The fourth chapter (Chapter 12) in this section comes from Kenneth Cafferkey, who demonstrates through his experiences using case studies that access and data collection do not come without the difficulties of interference from practitioners. He reveals how practitioners may prefer researchers to ask the questions the managers want, not the theoretically derived research agendas that we seek to deliver, emphasising the importance of having the right access for the right question. 
Getting data is one thing, but in the business-related fields of applied research we are often reliant upon collecting data from people in organisations for whom our research project is not their biggest problem. Our contributors provide seven vignettes for this section; the first of these (vignette 13) comes from Polly Black, who reveals why, when she was developing qualitative interviews, a pilot study was really necessary. Wojciech Kwiatkowski provides a story in vignette 14 that many researchers will appreciate, a tale of feeling strung along with the endless promises of physical access to collect data 'soon' that never comes to fruition. What do you do? When you do get access, can you be sure that it will be maintained? Not according to Ashlea Kellner who, in vignette 15, relays her experience of finding agreement with gatekeepers in seven organisations only to find her options shrinking and disappearing before her eyes.

Vignette 16 comes from Keith Townsend, who found himself in an interview with a recalcitrant employee, unwilling to offer anything to the research project. Given the project had reached the theoretically important point of saturation, the researcher decided that there was little point in persevering with the interview. Perhaps a different decision would have been made at a different point of the project, but that's why context is so important in the social sciences. In vignette 17 Catheryn Khoo-Lattimore wasn't going to take any chances with not having enough data collected, so she worked very hard in offering incentives to garner participation. Great idea until her examiner questioned whether the incentives were 'too lucrative': read her vignette to find out how she responded! Following this, we have Colin Hughes's vignette (18), which provides some hard lessons learnt during his doctoral research when being a researcher can often feel like being in sales. His vignette offers five valuable steps for the researcher to keep in mind when undertaking projects with practitioners. Before we move to the next section of the book, Qian Lee describes in vignette 19 being placed in the unenviable position of a senior manager continually rescheduling interview times before inviting a second interviewee in to the meeting. Sometimes split-second decisions must be made in data collection!

In our simple progression of the perfect project, we've managed to get started, got the data, now it's time for 'getting it together'. Our first chapter (20) in this section, '. . . Just one goat', brings an old joke in to modern academia. People interpret things differently, so this is something to be mindful of when you are interpreting your qualitative data, according to Keith Townsend and Rebecca Loudoun. What seems like a sensible idea at the start of data collection proved much more complicated for this project as the researchers found many people interpreted, and therefore responded to, the interview questions differently. 
Sameer Qaiyum and Catherine Wang have contributed a conversationstyle chapter (21) exploring issues of quantitative data analysis and issues associated with learning new statistical techniques. Sameer tells of times 'in the dark' and at least one 'wild goose chase' on their research project and the importance of thinking 'outside the box' when you are faced with problems of analysis. He also highlights how quantitative data analysis can be a messy business and that the associated learning is ongoing. And just when you think you have the analysis all covered: the writing - what if it doesn't just flow from the fingertips? We've all had those days in front of a white screen or written and deleted a sentence 17 times. In Chapter 22 Dawn Duke offers some insights for getting the writing part of your research project back on track 'when the words just won't come'. Emphasising that we all struggle with writing at some time [editors' note: we certainly both do!], she shares stories of researchers struggling with writer's block and, importantly, what helped them overcome this. Dawn also offers a series of excellent quotes, including fiction writer C.J. Cherryh musing: 'It is perfectly okay to write garbage - as long as you edit brilliantly'. Good advice for anyone struggling with a blinking cursor!

Our four vignettes in this section tell cautionary tales. Ilenia Bregoli reveals her affinity with feelings in a Led Zeppelin song about betrayal as she transitioned from paper to computer software for analysis (vignette 23), highlighting the need to really understand the analysis method used. In contrast, Rohit Talwar's story in vignette 24 emphasises the importance of making regular and frequent back-up copies. His cautionary tale of coffee and electronic devices tells of how a poorly designed coffee mug destroyed over three weeks of data analysis and associated writing. When you have your work written, sometimes it needs to be presented to humans and, according to Kenneth Cafferkey, that doesn't always go smoothly, particularly if one of your audience isn't really a 'people person' (vignette 25). Jennifer Kilroy, in Chapter 26, reminds us that sometimes the space for our research comes in the most peculiar places; nevertheless, we can often find these spaces when we plan well.

Well, the project seems to have gone well until now; we've got started, got the data, we've got our analysis completed and we've even got some writing done. Time for 'getting finished'. Getting finished sometimes requires wonderfully difficult conversations about authorship; just ask Kate Daunt and Aoife McDermott. Or better still, read Chapter 27, where these authors explore the complicated politics of authorship within academia, considering questions such as on what basis to award authorship and in what order and, crucially, what to do when things go wrong. These interpersonal tribulations are nothing compared to the internal struggle 
many of us feel when we pass our work to others for feedback (and that's before those pesky editors and reviewers!)

In Chapter 28 Amanda Lee provides us with an account of coming to terms with detailed feedback. More specifically, Amanda was convinced that one of her supervisors thought she was incapable of writing (which, when you read the chapter, you can see she is not) and struggled with managing her feelings, reactions to the feedback she was receiving, and her supervisor! Amanda embarked on a useful process of keeping a reflective research journal to help work through the difficulties that, as many of us can appreciate, affect motivation and confidence. Most of us develop 'thicker skins' as we progress through our career, but it is important to remember that the feedback we receive is rarely about us as people, but about the work that we've presented - an important distinction to make.

All the world is a stage, Shakespeare tells us, and academia is certainly verging on a pantomime sometimes. In Chapter 29, presented in three scenes, Kiran Trehan, Alex Kevill and Jane Glover explore issues associated with securing and maintaining research projects for researchers at different stages in their academic careers. For each career stage they reveal the messiness and complexities of keeping research projects on track and how, despite things going 'wrong', you just have to keep moving forward.

There's no question that the world has changed with the advent of 'smart' devices, phones, laptops and tablets. Billy Bragg has a lyric in a song voicing concern about 'smart bombs in the hands of dumb people'. Let's be more optimistic about the smart devices in the hands of educated people and, as Angelique Gatsinzi shows in Chapter 30, embrace what the 21st century has to offer. Here she offers tales of her use of social media as both a means of support and to enhance the development of her research projects. This is followed by Marian Baird, with a feminist tale of success in Chapter 31. Here she reflects on the lessons she has learned as a researcher, starting from her 'naive beginnings' and exploring her subsequent development when relating to clients and undertaking organisationbased research, revealing how the success really only came more than a decade after the initial research began.

As we head towards the end of this volume, Mark Saunders gives us some thoughts about rewriting. Drawing from Bruce Springsteen's autobiography, in vignette 32 Mark reveals how, like song writers with their lyrics, we write and rewrite each publication. Mark presents the process of development of a journal article that lived through 22 drafts before even being presented to a journal editor and which was finally published after 41 drafts. It may surprise readers to know that this introduction has also gone through a fair number of drafts ...

Finally, in vignette 33 Peter Jordan reflects on his experience with research 
students who claim to be 'over it'. Over what, Peter contemplates . . the writing, the process, the research, the idea of research as a career perhaps? After reading the trials and tribulations of our fellow researchers (and ourselves) in this introduction you may have started to wonder why on earth we even do this job and question whether we should be 'over it'. You may be thinking, surely it's too difficult. But the enthusiasm we had as we developed the idea for this volume was matched by the enthusiasm of the contributors who were not only excited about the project and their chapters but also wanted to tell what they considered to be the interesting tales of when things went wrong and offer insights from their real research experiences. That's why we do research, because although it rarely goes smoothly, it is almost always exciting and interesting. The reality of doing research is that 'shit happens'. Things will never go perfectly. But we have a job to do, so we draw on the dozens of researchers who've found out that when things go wrong, you will learn, and you will be able to get your research project back on track!

\section{NOTE}

1. There is a photograph of the pub on the back cover.

\section{REFERENCES}

Saunders, M.N.K. and Lewis, P. (1997), 'Great ideas and blind alleys? A review of the literature on starting research', Management Learning, 28(3), 283-99.

Townsend, K. and Burgess, J. (2009), Method in the Madness: Research Stories You Won't Read in Textbooks, Oxford: Chandos Publishing. 